\title{
Shareholding Networks for Care in Rural Thailand: Experiences of Older Persons and Their Family Members
}

\author{
Supaporn Voraroon1,2, Yaowaluck Meebunmak ${ }^{3}$, Ingela Enmarker ${ }^{4,5}$, Ove Hellzén1 \\ ${ }^{1}$ Department of Nursing Sciences, Mid Sweden University, Sundsvall, Sweden \\ ${ }^{2}$ Boromarajonani College of Nursing, Suphanburi, Thailand \\ ${ }^{3}$ Boromarajonani College of Nursing, Ratchaburi, Thailand \\ ${ }^{4}$ Faculty of Health and Occupational Studies, University of Gävle, Gävle, Sweden \\ ${ }^{5}$ Centre for Care Research Mid-Norway, Steinkjer, Norway \\ Email: ove.hellzen@miun.se
}

How to cite this paper: Voraroon, S., Meebunmak, Y., Enmarker, I. and Hellzén, O. (2017) Shareholding Networks for Care in Rural Thailand: Experiences of Older Persons and Their Family Members. Open Journal of Nursing, 7, 318-330.

https://doi.org/10.4236/ojn.2017.72026

Received: December 21, 2016

Accepted: February 25, 2017

Published: February 28, 2017

Copyright (c) 2017 by authors and Scientific Research Publishing Inc. This work is licensed under the Creative Commons Attribution International License (CC BY 4.0).

http://creativecommons.org/licenses/by/4.0/

\begin{abstract}
Most members of the older population in Thailand live in rural areas while their children live in cities. With the joint family system separated, elderly Thai persons often have to care for themselves, and opportunities for them to get involved in community care remain limited. In response, the aim of this study was to describe older persons' and their family members' experiences with shareholding networks for the care of older people in rural Thailand. Paired interviews with five older persons and five of their family members were conducted, and collected data were subjected to content analysis, which yielded results organized around two themes: older persons' outsider status and disregard for older persons' individuality. Whereas the theme of outsider status describes shortcomings in healthcare encounters, the theme of disregard for individuality describes the lack of engagement of authorities and caregivers in older persons' care. In that sense, the concept of participation emerged as a framework for understanding interviewees' experiences. Given findings from local authorities, older individuals and their family members should engage in dialogue in order to support healthcare based on shared understanding.
\end{abstract}

\section{Keywords}

Community Healthcare, Content Analysis, Older Persons, Participation

\section{Introduction}

The expansion of older and aging populations represents a major global demo- 
graphic trend [1], and Thailand is no exception. Thai seniors older than 60 years account for more than $16.7 \%$ of the national population and total approximately 10.92 million in number. Moreover, as estimations suggest, those figures will double in the next decade [2]. Most older Thai people live in rural areas, while their children live in cities, and with the joint family system separate, elderly often have to care for themselves. In general, Thailand's changing population structure has not only introduced numerous problems for healthcare in aging communities [3], but also threatened the marginalization of older people in society [4] and their health outcomes [5].

Despite national policy addressing the aging Thai population [6], no policy has yet afforded preparations of care for older people in their communities. As such, community networks of older people, their families, caregivers, and organizations have begun to play critical roles in spearheading and sustaining work processes associated with community-based healthcare for older people [7]. Individual engagement and networks have shown improvement in terms of caring for the health of the older population [8], and as Nuño et al. [9] have pointed out, shareholding networks in such care as perceived by older persons and family members in rural areas could be enhanced if the networks more clearly implemented the philosophy of innovative care for chronic conditions (ICCC). According to that philosophy, high-quality integrated care should be based on the most advanced evidence in order to improve care not only for those with chronic conditions, but for all [10] [11].

Older persons who receive community-based healthcare are often considered to need more assistance than those allotted by other forms of community care, which risks the activation of associated power differentials [12]. Such thinking relates closely to ageism [13], defined as a prejudice that, unlike other forms, affects all individuals once they reach an age at which they remind younger people of their own future aging and inevitable death [14]. Ageism threatens solder individuals' dignity - that is, their moral value closely connected with their integrity and autonomy. As an antidote, it is vital to let older people's voices be heard. Among other authors, Helgesen et al. [15] have stated that knowing patients is a crucial prerequisite for identifying the optimal level of participation for caretakers. Unsurprisingly, family members play important roles in transferring information and knowledge about older persons to healthcare authorities, and studies have even found that the importance of family in that capacity increases as older persons' functioning decreases or as their diseases progress [16] [17].

Despite the need for both individual and general knowledge about aging persons, no studies have addressed the experiences of shareholding networks for older persons' care in rural communities. However, capturing such knowledge could facilitate older persons' improved participation and increase their involvement in communal healthcare-opportunities that to date remain rather limited. By letting older persons and their family members narrate stories about their experiences with community healthcare, it is possible to glean a deeper understanding of the care that they receive and, in turn, improve the quality of 
their daily lives. Accordingly, the aim of this study was to describe older persons' and their family members' experiences in shareholding networks for the care of older people in rural areas.

\section{Method and Design}

Drawing upon conventions of qualitative research, this study gathered and interpreted persons' subjective experiences. The qualitative approach allowed the capture of nuances, details, and reflections undetectable by quantitative methods [18] [19].

\subsection{Participants and Context}

Following Malterud et al.'s [20] discussion of sample size and information power in qualitative studies, five older persons and five family members $(n=10)$ participated in this study. A convenient sample was recruited depending on willingness and on each person's cognitive appropriateness. Nurses in home nursing care were informed about the study. Both verbal and written information were provided. These nurses judged whether each older person's health status permitted participation. Persons who wished to participate send their consent directly to the researcher. The researcher then contacted the participant and practical arrangements were agreed upon. We included relatives were included if they lived with or considered themselves as close to selected older person. All eligible participants were given verbal and written information about the purpose and procedure of the study, and all were aged no less than 60 years, resided in a rural community in central Thailand, had at least 12 months of experience with shareholding networks, and could fully understand the purpose and content of the study. The sample of older persons was composed of two older women, both of whom were mothers, and three older men, two of whom were fathers; all were aged $67-79$ years (median $=74$ years). Meanwhile, the sample of family members $(n=5)$ consisted of five women-one wife and four daughters-aged 37 67 years (median $=49$ years).

The study was conducted in a rural subdistrict in central Thailand with a senior population of 927 , or approximately 48 older people per $\mathrm{km}^{2}$, which had increased from $10 \%$ of the total population in 2010 to nearly $15 \%$ by 2015 . The average income in the subdistrict where the study was conducted is approximately 8000 baht per month (210 EUR) and agricultural production is still high and the sector is important for employment. In the subdistrict, two primary government agencies provide healthcare services: local administrative organizations (LAOs), which provide basic healthcare services for older people in line with the government policy prescribed by health promotion hospitals (HPHs), which provide health promotion, prevention, treatment, and recovery services based on the criteria of the Ministry of Public Health.

\subsection{Data Collection}

The first author conducted paired interviews from May to October 2015. Initial- 
ly interviewees were asked to speak openly about their own or their relative's daily life. As their stories unfolded, more targeted questions:

- What do you think is important for older people's care in the community?

- What are some experiences that you have had with your care as an older person?

- What are some examples of health policy for older people's care in the area?

- How have community resources adequately helped to address needs identified by healthcare organizations in the community?

- Would you describe healthcare system methods for exchanging information and facilitating interactions in the community?

The interviews occurred in the participant's home. During interviews, the interviewer asked clarifying questions to support understanding or encourage interviewees to develop their responses. The first author conducted and audio taped all interviews, which lasted $60-80 \mathrm{~min}$, and transcribed them verbatim. All interviews were performed in Thai. The first author also translated the transcripts from Thai to English. The second author checked the translation and confirmed that the meaning was kept throughout the process. The language in this article is assured quality by professional editing.

\subsection{Data Analysis}

Transcribed interviews were subjected to thematic content analysis in compliance with Downe-Wamboldt's [21] protocol. Analysis began with several complete readings of the transcripts in order to gain a sense of their content, after which material responding to the aims of the study was identified, extracted, condensed, and coded. Coded meaning units were sorted and categorized based on similarities and differences in content over the course of several stages, all with constant reference to the original text in order to prevent the loss of aspects of the content. Primary analysis was performed by the first author, although all authors read the material as a means to reflect and discuss findings together. Analyses resulted in four categories grouped within two themes.

\subsection{Ethical Considerations}

The study followed the ethical principles of the Helsinki Declaration [22]. All participants were informed about the study and assured that their participation was voluntary and that they could withdraw from the study at any time. All participants gave their informed consent and were guaranteed confidentiality with an anonymous presentation of the findings. The research was approved by Thailand's Ethical Review Committee for Research with Human Subjects (IRB: SP 0032.002/4/3.1/2015).

\section{Results}

The aim of the study was to describe older persons' and their family members' experiences with shareholding networks dedicated to the care of older people in rural areas. Themes and categories are presented in what follows and illustrated 
by quotations from the interviews. An overview of themes and categories is presented in Table 1. Quotations refer to respective paired interviews.

\subsection{Older Persons' Outsider Status}

\subsubsection{Lack of Engagement and Interest}

Interviewees highlighted experiences involving difficulty with participating in older people's care, which they considered to threaten their dignity. Such situations involved conditions in which healthcare personnel showed no concern for interviewees' opinions:

The LAO programs for providing health services to older people is a program planned by the government. Maybe they have gotten new ideas for the program from the community, but senior citizens have little chance to express their opinions [older persons' experience of own care have no or little impact on program development of older persons' care]. (P3)

Living in a rural area demands engagement from healthcare; however, professionals too often assume that older persons can manage, for example, to get to activities by themselves, even when activities are far from home and no busses or relatives are available to transport them. Interviewees also described healthcare workers' lack of involvement in their personal health, which they considered a risk for and obstacle to positive healthcare encounters, including those intended to ensure ongoing care and future contact with healthcare workers. One interviewee even stated that

They [Healthcare workers] always say that they don't have time to participate. (P2)

Interviewees also reported that they received insufficient attention from others in the community and could not give voice to their ideas concerning elderly policies in their community. They generally added that the problem related to widespread disinterest among team members in subdistrict organizations regarding older peoples' social roles. They moreover emphasized that health service activities should grow out of older persons' experiences, not those of the government, which was a tendency that frustrated interviewees and left them unsatisfied. As one interviewee suggested in response,

It would be great if there were a place or way for older persons and their families to express their opinions about policies. (P5)

Interviewees additionally stressed that they never had been invited to partici-

Table 1. Overview of themes and categories constructed from paired interviews.

\begin{tabular}{cc}
\hline Themes & Categories \\
\hline Older persons' outsider status & Lack of engagement and interest \\
& Lack of resources \\
Disregard for older persons' individuality & Lack of responsibility \\
& Lack of communication \\
\hline
\end{tabular}


pate in community elderly care policies, yet nevertheless claimed that it was important for LAOs and community committees to recognize the values of older people and their family members' roles.

\subsubsection{Lack of Resources}

Interviewees highlighted older persons' need for supportive resources from community organizations in rural areas and stressed that older persons' self-care activities often were based on their economic situations. As one relative said:

Mouths and bellies have to come first. If we were to join in activities, then we'd have to stop working. That would cost us 300 Bath [approximately 8 Euro] a day. (P2)

Along with their economic situations, other aspects of the necessity of self-care were identified, including lack of knowledge and education about basic elements of healthcare-for example, blood pressure control:

I'm old, and I'm afraid to tell them [healthcare workers]. The people working in LAOs and HPHs have knowledge. They have studied a lot more than me. (P5)

The lack of resources moreover seems to create additional distance between older persons and their relatives, on the one hand, and between them and their communities on the other hand. As interviewees pointed out, that circumstance could further frustrate relatives and put them in impossible situations:

Relatives have to work. It's already dark when they get home. Sometimes it's like they're not interested in taking care of their elders. (P4)

\subsection{Disregard for Older Persons' Individuality}

\subsubsection{Lack of Responsibility}

According to interviewees, the causes of problems expressed generally relate to insufficient responsibility taken by staff in community care organizations. As they put it, LAOs and HPHs had failed to recognize their needs and, in turn, to manage the provision of healthcare services. As an antidote, they recommended that

Staff working in LAOs should create new healthcare services specifically for older persons in the area. (P1)

Interviewees moreover complained about the distance between them and the community organizations, as well as about the inappropriateness of routine work:

Staff do routine work only to meet their organization's criteria. (P3)

\subsubsection{Lack of Communication}

Interviewees discussed the lack of opportunities to have their voices heard and thereby actively participate in the care policy and services of their communities. They added in particular that LAOs' communication did not meet requirements 
or their needs as customers:

The government keeps to itself. It tells us to do what it wants... but it never asks what type of healthcare we need. Our older persons are different. For example, some bed-bound older persons have no interest in performing any activities, unlike our group members, who do everything to the fullest when we are told to. (P1)

It seems as though the lack of communication between officials and families had resulted in the stagnation of program content, which risked entrenching a sense of boredom and monotony:

The LAO programs for providing health services to older persons is a conventional program planned by the government. The programs are the same and without change for older persons in the area... The LAO takes care of senior citizens every year, but it's the same old program every year. When one year is up... There are no changes in the program. (P1)

Interviewees stressed that the best way for the government to present information was to ask questions, such as about what older persons want or what problems they have. In short, they stressed the importance of referring to older persons' needs when changing strategies or integrating LAO or HPH policies:

Planning activities and projects to care for the health of older persons in our community should be integrated with LAO and HPH work plans with a representative older person who participates by offering opinions during planning. (P4)

\section{Discussion}

This study focused on older persons' and their family members' experiences with being part of shareholding networks for the care of older people in rural areas in Thailand. Since the study took place in one subdistrict in one province with a small sample, it is important to bear in mind that the results of the study cannot be generalized, but should be seen as another argument in an ongoing discourse [23]. Nevertheless, the context can be conceived as a frame that represents how older persons and their family members experience healthcare services given by primary government agencies on a larger spectrum. The results show that the chief reasons for shortcomings in healthcare encounters, according to the interviewees, caused experiences of feeling barred and, in turn, a sense of having outsider status in their own communities. Interviewees stated that problematic experiences involved a lack of engagement, interest, resources, responsibility, and communication barriers among local administrative organizations and subdistrict health promotion hospitals regarding older persons' situations. In response, interviewees considered it to be important to be allowed to participate when the government plans care offerings and services.

Problems voiced by interviewees concerning cooperative networking for healthcare for older persons in the community were consistent with those re- 
ported by [24], who stated that power differentials between elderly persons and staff offering care for the elderly were a common reality that negatively influences elderly persons' independence and autonomy. Doyle [24] argued, with reference to Levy [13], that the problems connote ageism based in stereotypes of older individuals and aging. Since such assumptions by healthcare worker scan often prompt inferior therapeutic goals and reduce the quality of care given, it is critical to encourage an ethos in healthcare services for older people that prioritizes protecting human dignity [25]. According to Edlund [26], dignity and selfesteem are closely linked, and healthcare personnel should respect not only older persons' dignity, but also their role in giving dignity-supporting care [27].

The findings furthermore indicate that interviewees experienced receiving insufficient attention from others in the community and a lack of opportunities to express their ideas about elderly care policies in their communities. It seems as though elderly care policies in the community addressed have been built by following a top-down approach, which has led to a lower level of participation instead of an objective to promote older persons' and their families' participation in community activities. In that sense, the benefits of using the community participatory process in providing healthcare to community populations include developing healthcare policies for older people toward ensuring a process that gives opportunities to the target group to participate in solving their own health problems [10].

Interviewees also described their lack of resources essential for self-care activities. Based on our findings, it seems that involvement from local and regional authorities in the matter is invaluable. Of course, authorities need to be involved throughout the process, from planning to evaluation [28], yet they should also work closely with representatives of older people's groups in setting policy in the community [29]. In addition to this structural matter, older people and their families need practical support in the forms of help and knowledge with basic aspects of healthcare, including the control of blood pressure and blood glucose levels. Self-management and social support toward managing personal health are essential self-care activities that the World Health Organization stresses as important components to allow older people to care for themselves [10] [30].

Another important factor described by interviewees was their experiences with a shortage of financial support. Activities require funding to cover expenses, and economic support for projects is important in performing current work and making preparations for the future when building self-management programs for older people [31]. That LAOs and HPHs in Thailand receive partial financial support from the government demonstrates that the aforementioned projects are within the government's purview. Local authorities are an important resource for improving the development of services for older people that offer added community value. As such, all local authorities should develop a local asset strategy that sets out to involve older people in developing programs that facilitate their well-being and to encourage and promote the sustainable development of care services for older persons. Our findings highlight the need for 
more positive and imaginative government thinking and support in offering older persons community care that enhances well-being characterized by better mental and physical health and reduced dependence-that is, being in control, retaining independence, and feeling secure.

The findings also indicate that another problem encountered in older persons' experiences with healthcare is their and their families' sense of a disregard for their individuality. Older people and their family members sense a lack of responsibility among local authorities that has detrimentally influenced the quality and safety of healthcare services provided, particularly given the lack of consideration of them as unique individuals and stakeholders. To improve the care of older people, resources need to be developed not only by focusing on work with existing sources of care, but by also extending the rights of older people at least to include an assessment of needs and an equitable meeting of those needs with care services available [32].

Insufficient communication between local authorities and older people seems to be yet another problem. As our study indicates, older people and their families engage in inadequate, if any, communication with public employees working to provide healthcare for them and with others involved in the community. According to Lavoie et al. [33], people, especially healthcare professionals, are responsible for other people and therefore need to be attentive and focused on each individual person's specific needs. It is reasonable to assume that theLAO staff's unwillingness to listen to older people and their family members is due to the absence of channels for proper communication. That inference is in line with Olsen et al.'s [34] findings that an absence of place and channels for communication prompt routine-based work. An essential healthcare strategy should thus be to counteract that absence [35], which agrees with Martinsen's [36] argument that receptivity means that healthcare workers are present not only as interpreters of situations, but also as receivers of patients' concerns. As such, it is crucial to respond to each patient as a unique individual in order to provide effective healthcare [37] [34]. In that light, our findings address fundamental structures and values built into healthcare practices. According to Devik et al. [38], there is a great need to focus attention on the emotional dimension and how it influences healthcare and not only to focus on knowledge-based analyses of situations.

This study has revealed that the phenomenon of participation should be grounded in the idea of being master of one's own life, which is essential to all humans and important for the self-esteem and dignity of older people and their family members in particular. By extension, older people's and their family members' involvement in community healthcare can be understood according to the concept of participation. Local participation may be regarded as natural in community development approaches, both as a necessary condition for change and in terms of the values of empowerment and partnership [39]. According to Wakefield and Poland [40], there is a danger of non-reflexive practice in such participation approaches, however. Instead, another way to understand partici- 
pation is to highlight the social and psychological dimensions of healthcare as they relate to identity [41] and place [42]. At the same time, the phenomenon of participation might also be philosophically grounded in the idea of being master of one's own life, which is stressed as being essential to all human beings and, in our study, important for the self-esteem and dignity of older individuals in community care.

To protect older persons' self-esteem and dignity, the level of participation has to be adjusted to the individual's abilities at the particular time. From such a point of view, our findings can be understood in the light of Buber's [43] argument, which states that every human requires significance-that is, being placed in another's world. The findings indicate that one meaning of meeting an older person is that both parties occasionally participate in one another's lives and not only psychologically. According to Buber [43], recognizing the other's expressions is a manifest reality of the inter human dynamic. On such occasions, each actor turns to each other in order to communicate person-to-person.

\section{Limitations and Strengths}

A major strength of this study was paired interviews with older persons and family members, which functioned as springboards for more open discussions and was effectively uncovered older persons' experiences with healthcare. Furthermore, analyses were conducted jointly and reviewed independently by all authors, which added rigor to the study, and preliminary results were presented to interviewees to ensure rigor and ensure the credibility of data, as consistent with Lincoln and Gruba's [44] recommendation. However, because this qualitative study took place in a single subdistrict in only one province of Thailand with a limited number of participants, it is difficult to generalise the findings beyond the local context.

\section{Conclusion}

This paper has discussed the experiences of care for older people in rural areas in Thailand as perceived by them and their family members. The context can be conceived as a frame that represents how older persons and their family members experience healthcare services given by primary government agencies on a large scale. The results show that the chief reasons for shortcomings in healthcare encounters, according to the interviewees, caused experiences of feeling barred and, in turn, a sense of having outsider status in their own communities. Interviewees stated that problematic experiences involved a lack of engagement, interest, resources, responsibility, and communication barriers among local administrative organizations and subdistrict health promotion hospitals regarding older persons' situations. Furthermore, authorities should afford opportunities to hear out older persons' concerns when planning care offerings and services. It is therefore necessary to reflect on the concept of participation as a frame for understanding the experiences of interviewees in this study. On the basis of our findings, we suggest that local authorities and older individuals and family 
members engage in dialogue as part of a vital approach for healthcare based on shared understanding.

\section{Relevance to Clinical Practice}

Every old person is unique and should be offered positive healthcare encounters with good nursing care based on his or her personal experiences. Old persons therefore need to be met with understanding, presence, and engagement in their relationships with healthcare workers.

\section{Conflict of Interest}

The authors have no conflicts of interest to declare.

\section{References}

[1] World Health Organization (2015) Ageing and Health. http://www.who.int/mediacentre/factsheets/fs404/en/

[2] Institute for Population and Social Research (2016) Statistics on Aging in Thailand (on October 2016). Mahidol University, Thailand. http://www.thailandometers.mahidol.ac.th/

[3] Kuhirunyaratn, P. (2007) Social Support among Elderly in KhonKaen Province, Thailand. Department of Community Medicine, Faculty of Medicine, KhonKaen University, KhonKaen, Thailand. http://www.tm.mahidol.ac.th/seameo/2007 38 5/23-4021.pdf

[4] Ness, M.T., Hellzén, O. and Enmarker, I. (2014) Embracing the Present and Fearing the Future: The Meaning of Being an Oldest Old Woman in a Rural Area. International Journal of Qualitative Studies on Health and Well-Being, 9. https://doi.org/10.3402/qhw.v9.25217

[5] Goins, R.T., Williams, K.A., Carter, M.W., Spencer, S.M. and Solovieva, T. (2005) Perceived Barriers to Health Access among Rural Older Adults: A Qualitative Study. Journal of Rural Health, 21, 206-213. https://doi.org/10.1111/j.1748-0361.2005.tb00084.x

[6] National Commission on the Elderly (2009) The Second National Plan for the Elderly (2002-2021). Ministry of Social Development and Human Security, Thailand. http://ageingasia.org/wp-content/uploads/2015/07/The-2nd-National-Plan-onTheElderly-20021221-Thailand.pdf

[7] World Health Organization (2014) Regional Office for South-East Asia. Regional Strategy for Healthy Ageing: 2013-2018. World Health Organization, Geneva, 50 52. http://apps.searo.who.int/PDS DOCS/B5112.pdf?ua=1

[8] Yen, I.H., Michael, Y.L. and Perdue, L. (2009) Neighborhood Environment in Studies of Health of Older Adults: A Systematic Review, American Journal of Preventive Medicine, 37, 455-463. https://doi.org/10.1016/j.amepre.2009.06.022

[9] Nuño, R., Coleman, K., Bengoa, R. and Sauto, R. (2012) Integrated Care for Chronic Conditions: The Contribution of the ICCC Framework, Health Policy, 105, 55-64. https://doi.org/10.1016/j.healthpol.2011.10.006

[10] World Health Organization (2002) Innovative Care for Chronic Conditions: Building Blocks for Action: Global Report: Non-Communicable Diseases and Mental Health. http://www.who.int/chp/knowledge/publications/icccglobalreport.pdf

[11] Pan American Health Organization (2013) Innovative Care for Chronic Conditions: 
Organizing and Delivering High Quality Care for Chronic Non-Communicable Diseases in the Americas. PAHO, Washington DC.

http://www.paho.org/hq/index.php?option=com docman\&task=doc download\&gi $\underline{\mathrm{d}=21115 \& \text { Itemid }=270 \& \text { lang=en }}$

[12] Powell, J.L. (2009) Social Theory, Aging and Health and Welfare Professionals: A Foucaldian “Toolkit”. Journal of Applied Gerontology, 28, 669-682.

https://doi.org/10.1177/0733464809335596

[13] Levy, B.R. (2001) Eradication of Ageism Requires Addressing the Enemy within. Gerontologist, 41, 572-575. https://doi.org/10.1093/geront/41.5.578

[14] Palmore, E.B. (1999) Ageism: Negative and Positive. 2nd Edition, Springer, New York.

[15] Helgesen, A.K., Larsson, M. and Athlin, E. (2014) Patient Participation in Special Care Units for Patient Participation in Special Care Units for Persons with Dementia: A Losing Principle? Nursing Ethics, 21, 108-118. https://doi.org/10.1177/0969733013486796

[16] Woods, R.T., Keady, J. and Seddon, D. (2008) Involving Families in Care Homes: A Relationship-Centred Approach to Dementia Care. Jessica Kingsley, London.

[17] Helgesen, A.K., Larsson, M. and Athlin, E. (2013) How Do Relatives of Persons with Dementia Experience Their Role in the Patient Participation Process in Special Care Units? Journal of Clinical Nursing, 22, 1672-1681. https://doi.org/10.1111/jocn.12028

[18] Patton, M.Q. (2002) Qualitative Research \& Evaluation Methods. 3rd Edition, Sage, Thousand Oaks.

[19] McPherson, C.J. and Addington-Hall, J.M. (2004) How Do Proxies' Perceptions of Patients' pain, Anxiety, and Depression Change during the Bereavement Period? Journal of Palliative Care, 20, 12-19. https://www.ncbi.nlm.nih.gov/pubmed/15132071

[20] Malterud, K., Siersma, V.D. and Guassora, A.D. (2016) Sample Size in Qualitative Interview Studies: Guided by Information Power. Qualitative Health Research, 26, 1753-1760. https://doi.org/10.1177/1049732315617444

[21] Downe-Wambolt, B. (1992) Content Analysis: Method, Applications and Issues. Health Care for Women International, 13, 313-321. https://doi.org/10.1080/07399339209516006

[22] World Medical Association (2013) Declaration of Helsinki: Ethical Principles for Medical Research Involving Human Subjects. JAMA, 310, 2191-2194. https://doi.org/10.1001/jama.2013.281053

[23] Ricoeur, P. (1976) Interpretation Theory: Discourse and the Surplus of Meaning. Christian University Press, Fort Worth.

[24] Doyle, S. (2014) The Impact of Power Differentials on the Care Experiences of Older People. Journal of Elder Abuse \& Neglect, 26, 319-332. https://doi.org/10.1080/08946566.2013.875970

[25] Eriksson, K. (2001) Caring Science as an Academic Discipline. ÅboAkademi, Vasa. (In Swedish)

[26] Edlund, M. (2002) Human Dignity. ÅboAkademi, Vasa. (In Swedish)

[27] Slettebø, Å. (2012) Ethical Challenges in Patients and Caregivers Encounters. In: Solvang, P.K. and Slettebø, Å., Eds., Rehabilitation, GyldendalAkademisk, Oslo. (In Norwegian)

[28] Muenhor, C. (2012) Community Participation: The Health Promotion Plan for El- 
derly. Journal of Community Development Research, 5, 43-54.

http://www.journal.nu.ac.th/index.php?journal=JCDR\&page=article\&op=view\&pat h\%5B\%5D=409\&path\%5B \%5D=424

[29] Baeza, J., Bailie, R. and Lewis, J.M. (2009) Care for Chronic Conditions for Indigenous Australians: Key Informants' Perspectives on Policy, Health Policy, 92, 211-217. https://doi.org/10.1016/j.healthpol.2009.03.012

[30] Sharma, J. (2013) Chronic Disease Management in the South East Asia Region: A Need to Do More. WHO South-East Asia Journal of Public Health, 2, 79-82. https://doi.org/10.4103/2224-3151.122935

[31] Barnes, M., Gahagan, B., Ward, H. and Ward, L. (2013) Older People, Well-Being and Participation Learning Resources Based on Collaborative Research. University of Brighton, Age UK Brighton \& Hove.

http://www.brighton.ac.uk/sass/older-people-wellbeing-and-participation/

[32] Blackman, T. (2000) Defining Responsibility for Care: Approaches to Care of Older People in Six European Countries. International Journal of Social Welfare, 9, 181-190. https://doi.org/10.1111/1468-2397.00127

[33] Lavoie, M., De Koninck, T. and Blondeau, D. (2006) The Nature of Care in Light of Emmanuel Levinas. Nursing Philosophy, 7, 225-234.

https://doi.org/10.1111/j.1466-769X.2006.00279.x

[34] Olsen, R.M., Østnor, B.H., Enmarker, I. and Hellzen, O. (2012) Barriers to Information Exchange during Older Patients' Transfer: Nurses' Experiences. Journal of Clinical Nursing, 22, 2964-2973. https://doi.org/10.1111/jocn.12246

[35] Subašic, E., Reynolds, K., Reicher, S. and Klandermans, B. (2012) Where to from Here for the Psychology of Social Change? Future Directions for Theory and Practice. International Society of Political Psychology, 33, 61-74. https://doi.org/10.1111/j.1467-9221.2011.00864.X

[36] Martinsen, K. (1993) The Caring Nurse. Tano, Oslo. (In Norwegian)

[37] Suhonen, R., Välomäki, M. and Katajiosto, J. (2000) Individualised Care in a Finnish Healthcare Organization. Journal of Clinical Nursing, 9, 218-227. https://doi.org/10.1046/j.1365-2702.2000.00362.x

[38] Devik, A.S., Enmartker, I. and Hellzen, O. (2013) When Expressions Make Impressions: Nurses' Narratives about Meeting Severely Ill Patients in Home Nursing Care: A Phenomenological-Hermeneutic Approach to Understanding. International Journal of Qualitative Studies and Health Well-Being, 8, 1-11. https://doi.org/10.3402/qhw.v8i0.21880

[39] Dinham, A. (2005) Empowered or Over-Powered? The Real Experiences of Local Participation in the UK's New Deal for Communities. Community Development Journal, 40, 301-312. https://doi.org/10.1093/cdj/bsi019

[40] Wakefield, S.E.L. and Poland, B. (2005) Friend, Family or Foe? Critical Reflections on the Relevance and Role of Social Capital in Health Promotion and Community Development. Social Science \& Medicine, 60, 2819-2832. https://doi.org/10.1016/j.socscimed.2004.11.012

[41] Habjanic, A. (2007) Challenges for Institutional Elder Care in Slovenian Nursing Homes. Journal of Clinical Nursing, 21, 2579-2589. https://doi.org/10.1111/j.1365-2702.2011.04044.x

[42] Campbell, C. and Murray, M. (2004) Community Health Psychology: Promoting Analysis and Action for Social Change. Journal of Health Psychology, 9, 187-195. https://doi.org/10.1177/1359105304040886

[43] Buber, M. (1994) I and Thou. DualisFörlag AB, Ludvika. (In Swedish)

[44] Lincoln, Y.S. and Guba, E.G. (1985) Naturalistic Inquiry. Sage, Newbury Park. 
Submit or recommend next manuscript to SCIRP and we will provide best service for you:

Accepting pre-submission inquiries through Email, Facebook, LinkedIn, Twitter, etc. A wide selection of journals (inclusive of 9 subjects, more than 200 journals)

Providing 24-hour high-quality service

User-friendly online submission system

Fair and swift peer-review system

Efficient typesetting and proofreading procedure

Display of the result of downloads and visits, as well as the number of cited articles Maximum dissemination of your research work

Submit your manuscript at: http://papersubmission.scirp.org/

Or contact ojn@scirp.org 